\title{
Hydrogen Evolution on Columnar Ni Thin Films Obtained by GLAD
}

\author{
Jelena Potočnik ${ }^{1}$, Maja Popović ${ }^{1}$, Zlatko Rakočević ${ }^{1}$, Svetlana Štrbac ${ }^{2, *}$ \\ ${ }^{1}$ INS Vinča, Laboratory of Atomic Physics, University of Belgrade, Mike Alasa 12-14, \\ 11001 Belgrade, Serbia \\ ${ }^{2}$ ICTM-Institute of Electrochemistry, University of Belgrade, Njegoševa 12, 11000 Belgrade, Serbia \\ *E-mail: sstrbac@tmf.bg.ac.rs
}

doi: $10.20964 / 2017.06 .89$

Received: 20 March 2017 / Accepted: 18 April 2017 / Published: 12 May 2017

\begin{abstract}
Nanostructured nickel thin films were deposited on glass using glancing angle deposition (GLAD) technique. Cross-sectional field emission scanning electron microscopy images have shown that obtained Ni thin films consist of vertical, tilted or zigzag nano-scaled columns, while X-ray diffraction have shown that (111) orientation prevailed. X-ray photoelectron spectroscopy revealed that apart from metallic nickel, $\mathrm{NiO}$ and $\mathrm{Ni}(\mathrm{OH})_{2}$ were also present in lower amount. Cyclic voltammetry in alkaline solution has shown that hydrogen evolution reaction (HER) was significantly catalyzed on all columnar nanostructures compared to $\mathrm{Ni}$ (poly). This was ascribed to the high electroactive surface area (EASA) of porous nickel columns. EASAs for vertical, tilted and zigzag Ni thin layers were higher 32, 25.3, and 24.9 times, respectively, than their geommetric areas. Accordingly, Ni thin films with vertical columns have shown the highest activity for HER.
\end{abstract}

Keywords: nickel thin films, glancing angle deposition, hydrogen evolution reaction, alkaline solution

\section{$\underline{\text { FULL TEXT }}$}

(C) 2017 The Authors. Published by ESG (www.electrochemsci.org). This article is an open access article distributed under the terms and conditions of the Creative Commons Attribution license (http://creativecommons.org/licenses/by/4.0/). 